\title{
The effect of decylcyclopropene derivative on the softening of 'Fuyu' persimmon fruits
}

\author{
Seong-Jin Choi ${ }^{1 *}$, Gwang-Hwan $\mathrm{Ahn}^{2}$ \\ ${ }^{1}$ Department of Biotechnology, Catholic University of Daegu, Gyeongsan 38430, Korea \\ ${ }^{2}$ Sweet Persimmon Research Institute, Gyeongnam ARES, Gimhae 50871, Korea
}

\section{Decylcyclopropene 유도체가 부유 단감 과실의 연화에 미치는 영향}

\author{
최성진 ${ }^{1 *} \cdot$ 안광환 $^{2}$ \\ ${ }^{1}$ 대구가톨릭대학교 생명공학과, ${ }^{2}$ 경남농업기술원 단감연구소
}

\begin{abstract}
In order to develop a sprayable ethylene antagonist, unlike 1-methylcyclopropene (MCP), we synthesized 2-decylcyclopropene-1-carboxylic acid ethyl ester (DCPE) as a derivative of cyclopropene and tested its effect on the flesh softening of 'Fuyu' persimmon fruits. The fruits on trees were sprayed with $4 \cdot 10^{-4} \mathrm{M}$ DCPE solution before harvest. After harvest, the persimmon fruits were stored at a low temperature for 1.5 months. The ripening progress of the fruits was then evaluated during storage at ambient temperature $\left(20^{\circ} \mathrm{C}\right)$. Flesh softening, a measure of ethylene response, was considerably delayed up to 7 days after DCPE treatment. However control fruits was rapidly softened after 3-day storage. The treatment effect of DCPE at $4 \cdot 10^{-4} \mathrm{M}$ was also compared to that of 1-MCP at $1 \mathrm{ppm}$. DCPE was storable at refrigerated conditions for at least one month without any loss. The results show that DCPE could be a potential sprayable agent for the prevention of flesh softening of persimmon fruit.
\end{abstract}

Key words : decylcyclopropene derivative, ethylene antagonist, Fuyu, flesh softening

\section{서 론}

식물은 에틸렌에 반응하여 다양한 생리적 변화를 일으킨 다(1). 식물의 에틸렌에 대한 반응은 에틸렌 수용체 단백질 (ETR1, ETR2, ERS1, ERS2, EIN4)의 매개를 통해 일어나는 데 $(2,3)$, 에틸렌 수용체는 평소 에틸렌과 결합하지 않은 조 건에서는 에틸렌 반응을 억제하는 음성 조절자의 역할을 한다. 그러나 에틸렌 수용체에 에틸렌이 결합하여 에틸렌 신호가 감지되면 이러한 억제 기능이 해제되어 하류의 신호 전달 경로가 활성화됨으로써 노화 또는 성숙 등과 같은 에틸렌에 대한 생리적 반응이 나타난다 $(4,5)$.

Olefin 계열의 고리화합물 중에는 탄소간 결합각이 안정

*Corresponding author. E-mail : sjchoi@cu.ac.kr Phone : 82-53-850-3548, Fax : 82-53-850-3548

Received 13 November 2014; Revised 17 October 2015; Accepted 16 November 2015.

Copyright (c) The Korean Society of Food Preservation. All rights reserved.
적인 $109.5^{\circ}$ 보다 좁아서 구조적으로 압박(strain) 상태에 있 는 화합물이 있다. 이러한 strain 상태에 있는 cyclic olefin이 식물의 에틸렌에 대한 반응을 억제한다는 사실은 Silsler와 $\operatorname{Pian}(6)$ 에 의해 처음으로 보고되었다. 그 후, Sisler와 Yang(7)은 strain이 심한 화합물일수록 수용체 단백질의 결 합 부위에 강하게 결합할 뿐만 아니라 에틸렌 반응을 억제 하는 활성이 증가한다는 사실을 발견하였다. 이러한 발견 을 근거로 하여 Sisler는 높은 ring strain 상태에 있을 것으 로 예측되는 화합물을 체계적으로 조사함으로써 식물의 에틸렌에 대한 반응을 강하게 억제하는 신물질로서 1methylcyclopropene(1-MCP)을 발견하게 되었으며(8), 1-MCP 는 오늘날 원예산물의 저장성을 향상시키는 에틸렌 작용 억제제로 널리 활용되고 있다.

Climacteric 형으로 분류되는 단감 과실은 같은 유형에 속하는 사과나 복숭아, 토마토 등의 과실에 비하면 매우 낮은 수준의 에틸렌을 생성함에도 불구하고 에틸렌에 예민 하게 반응하는 특징을 보인다(9). 대부분의 과실에서 과육 의 연화는 특히 에틸렌에 매우 민감하게 반응하여 나타나는 
성숙 현상인데(10), 감에서도 과육의 연화에는 에틸렌의 작용이 직접적으로 관련되어 있는 것으로 알려져 있다 $(11,12)$. 따라서 과육의 연화를 억제하고 저장성을 향상하 기 위하여 에틸렌의 작용을 차단하는 방법이 효과적으로 적용될 수 있는데, Takata(13)는 에틸렌의 작용을 억제하는 기능이 있는 은 이온(14)에 의해 부유 단감의 연화가 억제되 는 것을 보고한 바 있으며, 에틸렌 작용 억제제로서의 1-MCP 또한 단감 또는 떫은 감의 수확 후 에틸렌의 생성과 호흡을 억제하고 연화를 지연하는 것으로 보고되어 있다 $(9,15,16)$. 그러나 $1-\mathrm{MCP}$ 는 탁월한 효과와 그에 따른 실용 성에도 불구하고 실제 활용에 있어서 몇 가지 제약이 있다. $1-\mathrm{MCP}$ (분자량 54$)$ 는 액체 질소(-195 $\left.{ }^{\circ} \mathrm{C}\right)$ 에 동결된 상태나 불활성 가스에 희석한 상태에서는 비교적 안정하지만 -2 $0^{\circ} \mathrm{C}$ 에서 액화한 상태에서도 상당히 불안정하여 자가 중합 을 일으키며(22), 비등점은 $10^{\circ} \mathrm{C}$ 로서 상온에서 기체로 존재 한다. 따라서 1-MCP는 cyclodextrin과 같은 담체 분자 (capsule)에 개별 분자를 격리하여 고정(encapsulaton)시킨 상태(상품명 EthylBloc 또는 SmartFresh, 17)에서만 실용적 인 보존과 사용이 가능하다. 또한, 물에 거의 녹지 않아 액상으로 분무 살포 또는 침지 처리가 사실상 어려워서 기체 상태로 처리되어야 하므로 별도의 밀봉 처리나 밀폐 시설이 요구된다. 본 연구에서는 1-MCP의 이러한 단점을 보완하여 안정적으로 장기간 보존이 가능하고 상온에서 액상으로 조제하여 분무 살포가 가능한 새로운 형태의 에틸 렌 작용억제제를 개발하고자 하였으며, 이를 위하여 cyclopropene에 속하는 화합물의 하나로서 2-decylcyclopropene1-carboxylic acid ethyl ester(DCPE)을 합성한 후 이 화합물 이 단감 과실의 수확 후 과육의 연화에 미치는 영향을 조사 하였다.

\section{재료 및 방법}

2-Decylcyclopropene-1-carboxylic acid ethyl ester(DCPE) 의 합성 및 정제

실험에 이용한 DCPE는 Liao 등(18)의 방법으로 합성하 였다(Fig. 1), 둥근 flask에 $0.2 \mathrm{mmol}$ 의 rhodium acetate dimer 와 $50 \mathrm{mmol}$ 의 1-dodecyne을 넣은 후, $50 \mathrm{mmol}$ 의 ethyl diazoacetate를 $10 \mathrm{~mL}$ 의 dichloromethane과 혼합하여 syringe pump를 이용하여 $1.5 \mathrm{~mL} / \mathrm{h}$ 의 유속으로 주입하였다. 주입 종료 후, 반응물을 원심분리하여 rhodium acetate를 제거하였으며 $30^{\circ} \mathrm{C}$ 에서 rotary evaporator를 이용하여 dichloromethane을 증발시키고 남은 $\mathrm{DCPE}$ 를 회수하였다. 회수한 DCPE는 flash chromatography(19)를 이용하여 분리 정제하였으며 flash chromatography의 분리 조건은 다음과 같았다: column 내경 $=25 \mathrm{~mm}$; 충진제 $=30 \mathrm{~g}$ silica 60(high purity, 35 75 $\mu \mathrm{m}$ ); 용매 $=5 \%$ ethyl acetate/hexane; 용매
유속 $=5 \mathrm{~cm} / \mathrm{min}$; sample volume $=2 \mathrm{~mL}$; fraction volume $=20 \mathrm{~mL}$. Flash chromatography로 분리한 각 fraction은 $\mathrm{LC}-\mathrm{MS}$ 를 이용하여 분석하였으며 이 때 LC-MS의 분석 조 건은 다음과 같았다: HPLC = Waters 2695(USA); column = X-Bridge $(2.1 \mathrm{~mm} \times 5 \mathrm{~cm}, 3.5 \mu$, Waters, Milford, MA, USA); 용매 $=0.1 \%$ formic acid/acetonitrile(75/25 - 15/85, v/v); 유속 $=0.1 \mathrm{~mL} / \mathrm{min}$, sample volume $=1 \mu \mathrm{L} ; \mathrm{MS}=$ Waters 3100(USA); ionization mode = ESI+. DCPE를 함유한 fraction은 $30^{\circ} \mathrm{C}$ 에서 rotary evaporator를 이용하여 용매를 증발시켰으며, 최종적으로 회수한 $\mathrm{DCPE}$ 는 $\mathrm{GC}-\mathrm{MS}$ 를 이용 한 질량분석을 통하여 동정 확인하였다. 이 때 GC-MS의 분석 조건은 다음과 같았다: $\mathrm{GC}=$ Agilent $7890 \mathrm{~A}(\mathrm{Santa}$ Clara, CA, USA); column = DB-1(0.32 mm×30 m $0.5 \mu \mathrm{m}$ FT, J\&W Scientific, Santa Clara, CA, USA); column 온도 $=50^{\circ} \mathrm{C} 2 \mathrm{~min} \rightarrow 20^{\circ} \mathrm{C} / \mathrm{min} \rightarrow 240^{\circ} \mathrm{C}$; carrier gas $=\mathrm{He} ; \mathrm{He}$ linear velocity $=30 \mathrm{~cm} / \mathrm{sec}$; injector 온도 $=280^{\circ} \mathrm{C}$; split ratio $=1 / 20$; sample volume $=1 \mu \mathrm{L}(0.1 \%$ in dichloromethane $)$; MS = Agilent 5975C(USA); ionization mode = EI $70 \mathrm{eV}$. 정제한 $\mathrm{DCPE}$ 는 실험에 이용할 때 까지 $-70^{\circ} \mathrm{C}$ 에 보관하였 다. 한편, $\mathrm{DCPE}$ 의 안정성을 확인하기 위하여, 정제한 $\mathrm{DCPE}$ 를 실온, $4^{\circ} \mathrm{C},-20^{\circ} \mathrm{C},-70^{\circ} \mathrm{C}$ 에 각각 한달간 보관한 후 $\mathrm{GC}$ 로 분석하여 피크 면적의 변화를 조사하였다. 이 때 $\mathrm{GC}$ 분석 조건은 다음과 같았다: $\mathrm{GC}=$ Shimadu GC-2010; column $=\mathrm{AT}-5(0.32 \mathrm{~mm} \times 30 \mathrm{~m} 0.25 \mu \mathrm{m} \mathrm{FT}$, Alltech); column 온도 $=40^{\circ} \mathrm{C} 0.5 \mathrm{~min}, 20^{\circ} \mathrm{C} / \mathrm{min}, 240^{\circ} \mathrm{C} 3 \mathrm{~min}$; carrier gas $=\mathrm{N}_{2}$; $\mathrm{N}_{2}$ linear velocity $=34 \mathrm{~cm} / \mathrm{sec}$; injector 온도 $=250^{\circ} \mathrm{C}$; split ratio $=1 / 10$; sample volume $=1 \mu \mathrm{L}(0.1 \%$ in dichloromethane $)$; detector $=$ FID $280^{\circ} \mathrm{C}$.

\section{단감 과실의 $\mathrm{DCPE}$ 및 1-MCP 처리와 조사}

경남 진영 소재 단감연구소의 과원에서 관행적 방법으로 재배된 부유 단감 과실(Diospyros kaki, 'Fuyu')을 DCPE 및 $1-\mathrm{MCP}$ 의 처리에 이용하였다. 계면 활성제와 함께 희석한 $\mathrm{DCPE}$ 수용액을 11 월 초에 수확 전의 부유 단감 과실(40 $\mathrm{kg}$ )에 수상에서 분무 살포 처리하였다. $\mathrm{DCPE}$ 의 처리 농도 는 $4 \times 10^{-4} \mathrm{M}$ 로 하였으며, 계면 활성제는 $0.1 \%$ 의 실루엣 (30\% siloxane, Dongu Inc., Seoul, Korea)으로 하였다. 처리 한 과실은 1 주일 후 수확하였다. 한편, 대조구로서, 수확 직후의 무처리 과실(40 kg)에 대하여 관행적인 처리방법(9) 에 따라 SmartFresh(Rohm and Haas Korea)를 이용하여 1 $\mathrm{ppm}$ 의 $1-\mathrm{MCP}$ 를 처리하였다. 처리한 과실은 $20 \mathrm{~kg}$ 씩 저장 용 플라스틱 상자에 담아 45 일간 저온저장 $\left(0^{\circ} \mathrm{C}\right)$ 한 후 약 $20^{\circ} \mathrm{C}$ 의 실온에 1 주일간 방치하면서 색도, 당도 및 경도의 경시적 변화를 각각 색차계(CR-300, Minolta, Osaka, Japan), 당도계(Atago, Tokyo, Japan), rheometer(Compac-100II, Sun Scientific Co., Ltd., Tokyo, Japan)를 이용하여 측정하였다. 모든 측정에는 9 개의 과실을 이용하였다. 


\section{결과 및 고찰}

\section{$\mathrm{DCPE}$ 의 합성과 물리적 특성}

재료 및 방법에서 기술한 합성 반응의 최종 산물에 대하 여 GC-MS를 이용하여 mass spectrum을 분석한 결과(Fig. 2), 예상되는 분자량에 해당하는 molecular ion과 daughter ion이 검출되어 목적하는 $\mathrm{DCPE}$ 가 성공적으로 합성되었음 을 확인할 수 있었다. 합성 반응의 수율은 $80 \%$ 이상이었으 며 flash chromatography로 정제한 후의 최종 순도는 GC chromatogram의 피크 면적을 기준으로 $99.5 \%$ 이상이었다. 정제한 $\mathrm{DCPE}$ 는 상온에서 액상이었으며, 비등점을 직접 측정하지는 않았으나 비등점이 $166^{\circ} \mathrm{C}$ 인 1-dodecyne보다는 적어도 $50^{\circ} \mathrm{C}$ 이상 높을 것으로 추정된다. 한편, $\mathrm{DCPE}$ 를 실온에 한달간 보관한 후 $\mathrm{GC}$ 를 이용하여 분석하였을 때, 피크 면적을 기준으로 약 $30 \%$ 의 성분 손실이 나타났으나 $4{ }^{\circ} \mathrm{C}$ 이하의 온도에서 보관한 경우에는 손실이 나타나지 않았다. 따라서 DCPE는 다른 종류의 cyclopropene 유도체 특히 1-MCP에 비하여 상당히 안정한 화합물인 것으로 추 정된다. 비등점이 $-35^{\circ} \mathrm{C}$ 인 cyclopropene은 비등점 이상으로 온도를 높이면 폭발적으로 자가중합이 일어날 만큼 매우 불안정한 화합물(20)임에도 불구하고, DCPE가 이러한 안 정성을 보이는 이유는 carboxyl ethyl기와 decyl기의 치환 때문인 것으로 생각된다.

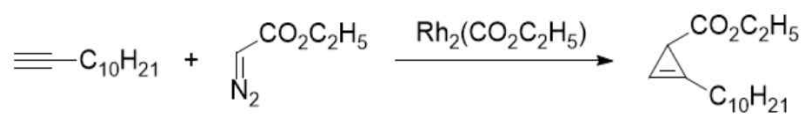

Fig. 1. Synthesis of 2-decylcyclopropene-1-carboxylic acid ethyl ester.

$\mathrm{DCPE}$ 의 수확 전 분무 살포가 저장 부유 단감 과실의 성 숙에 미치는 영향

부유 과실은 저온저장 중에는 에틸렌의 생성이 미미하고 성숙과 관련된 품질의 변화도 크지 않지만 일정 기간 동안 저온저장을 경과한 과실을 상온에 노출할 경우 에틸렌 생성 의 증가와 더불어 급속하게 품질이 저하되어 상품성을 잃는 것으로 보고되어 있다(9). 따라서 본 연구에서는 수확 전 수상에서 $\mathrm{DCPE}$ 를 액상으로 분무 처리한 부유 과실을 저온 에서 45 일간 저장한 후 상온에 1 주일간 노출하였을 때 처리 효과를 무처리 및 1-MCP 처리 과실과 비교하였다.

과피의 색도를 조사한 결과에서(Fig. 3), 1-MCP 또는 $\mathrm{DCPE}$ 의 처리는 상온 노출 기간 중에 녹-적색의 색차인 Hunter a 값에서는 처리간에 큰 차이가 없었으며 단지 색의 밝기를 보이는 Hunter L 값이나 청-황색의 색차를 보이는 Hunter b 값은 무처리에 비해 약간 높게 유지되었다. 그러나 경험적으로 단감 과실에서 육안으로 구별되는 색감의 차이 는 주로 Hunter a 값에 의해 결정된다는 점에 비추어 볼 때, $1-\mathrm{MCP}$ 또는 DCPE의 처리는 단감의 색도 변화에는
크게 영향을 미치지 않는 것으로 생각된다. 한편, 당도의 변화를 조사한 결과(Fig. 4)에서, 상온 노출 기간 중 당도는 전반적으로 약간 상승하는 경향을 보였으나 처리간의 차이 는 뚜렷하지 않았다. 그러나 색도 또는 당도의 경우와는 달리, 과육의 경도 변화를 조사한 결과(Fig. 5)에서는 무처 리와 처리간에 뚜렷한 차이를 보여서 무처리 과실의 경우 상온 노출 3 일 이내에 연시 수준으로 연화가 급속하게 진행 된 반면 1-MCP 또는 DCPE 처리구에서는 1 주일 동안 과육 의 연화가 거의 일어나지 않았다. 에틸렌 작용을 매우 효과 적으로 억제하는 것으로 알려진 1-MCP 처리에 대해 부유 과실이 보이는 이러한 반응은 색도 또는 당도의 변화에 에틸렌은 큰 영향을 미치지 않는 반면 과육 연화의 진행은 에틸렌의 작용과 밀접한 관련이 있음을 보인다. 한편, $\mathrm{DCPE}$ 처리에 대해 부유 단감 과실은 색도, 당도, 경도 등의 변화에 있어서 1-MCP 처리와 유사한 반응을 보였으며 특 히 1-MCP와 대등한 수준으로 과육 연화의 진행을 억제한 점에 비추어 볼 때 부유단감 과실에서 DCPE는 효과적으로 에틸렌의 작용을 억제하여 성숙을 지연하는 것으로 생각된 다.

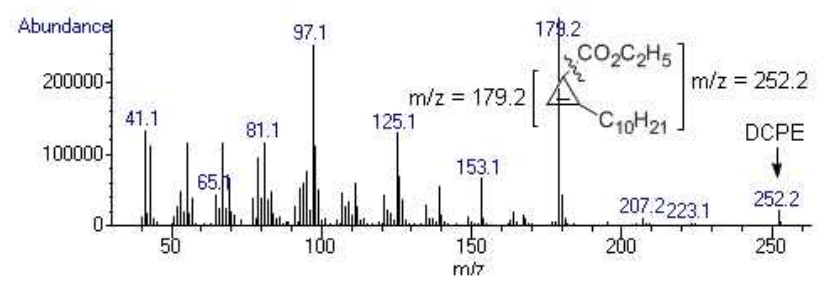

Fig. 2. Mass spectrum of synthesized DCPE.

Inserted figure shows the predicted $\mathrm{m} / \mathrm{z}$ of molecular and fragment ions, and arrow indicates the peak of molecular ion.

\section{$\mathrm{DCPE}$ 의 작용성 및 활용성}

서론에서 언급한 바와 같이, 식물에서 에틸렌 반응은 에 틸렌이 수용체 단백질의 결합부위(binding site)에 결합함으 로써 비롯된다. 에틸렌 수용체의 결합부위는 구리 이온을 함유하고 있으며 $(3,21)$, 에틸렌은 구리의 d orbital 전자를 자신의 $\pi$ 결합 궤도에 받아들이는 back bonding에 의해 구리이온과 결합한다. Sisler 등(21)의 이론에 따르면, 결합 부위의 구리이온에 결합한 에틸렌은 구리의 전하 분포를 변화시켜 리간드의 재편을 일으킨 후 자신은 분리되며 이로 써 에틸렌 신호전달 기작이 촉발된다. 그러나 1-MCP를 비 롯한 에틸렌작용 억제물질은 에틸렌과 달리 결합부위의 구리이온에 결합한 후 분리되지 않고 결합 상태를 지속적으 로 유지하는데 이 경우 에틸렌 신호전달 기작은 촉발되지 않는다. 따라서 에틸렌 작용 억제물질은 에틸렌 수용체의 구리이온에 강하게 결합하는 성질을 가져야 하는데 이러한 결합력은 그 물질의 strain energy와 관련이 있다. Cyclopropene 은 대표적으로 strain energy가 높은 화합물이며 본 연구에 서 합성한 DCPE는 cyclopropene 유도체의 하나인데, 

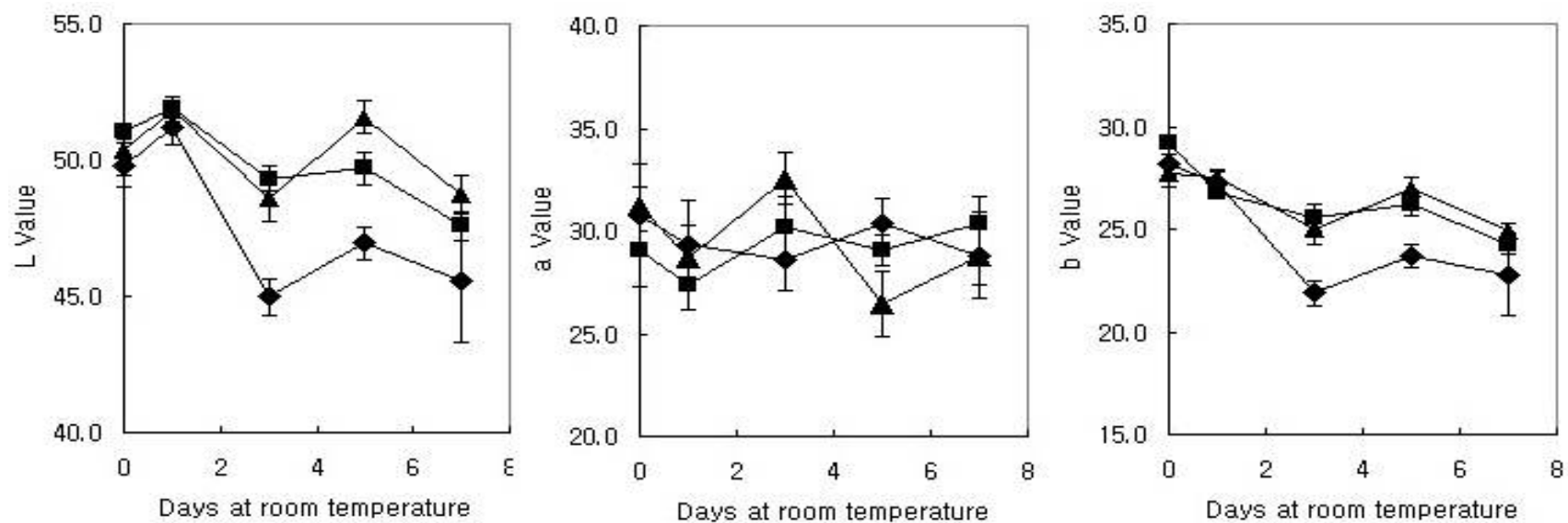

Fig. 3. Color change of 'Fuyu' persimmon fruits at room temperature.

The fruits were stored for 1.5 months at low temperature prior to analysis. Treatments: Control , DCPE

1-MCP $(\mathbf{\Delta})$. Vertical bars show SE $(\mathrm{n}=9)$.

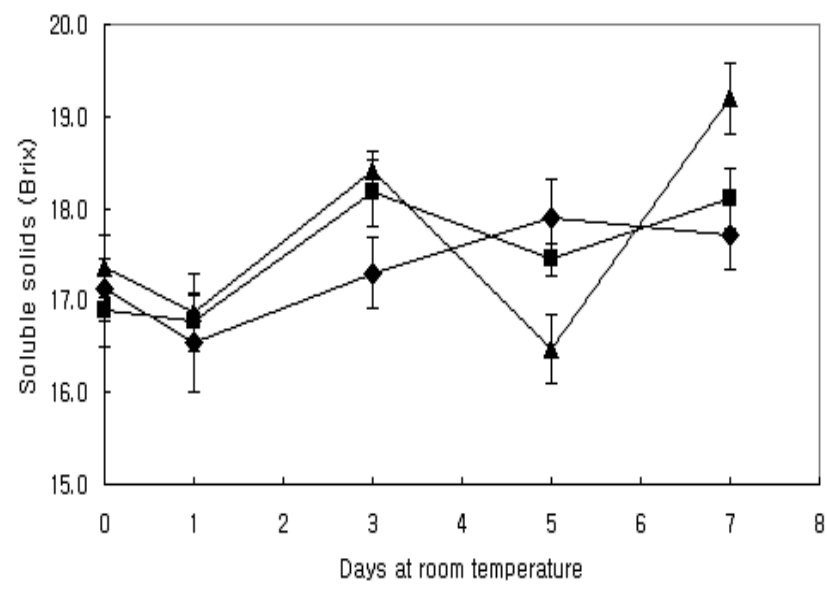

Fig. 4. Change in soluble solid content of 'Fuyu' persimmon fruits at room temperature.

The fruits were stored for 1.5 months at low temperature prior to analysis. Treatments: Control $(\boldsymbol{\nabla})$, DCPE $(\square), 1-M C P(\boldsymbol{\Delta})$. Vertical bars show SE $(\mathrm{n}=9)$.

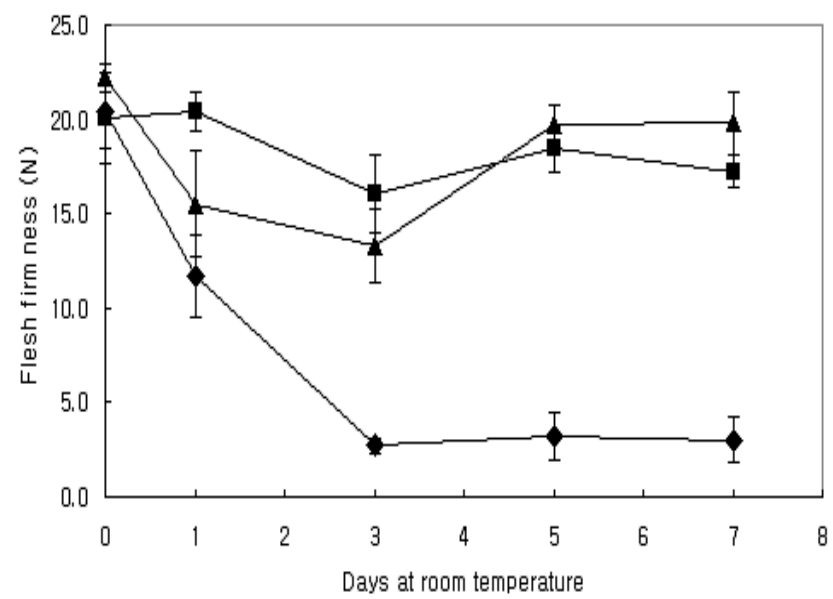

Fig. 5. Change in soluble solid content of 'Fuyu' persimmon fruits at room temperature.

The fruits were stored for 1.5 months at low temperature prior to analysis. Treatments: Control $(\boldsymbol{)})$, DCPE $(\boldsymbol{\square})$, 1-MCP $(\boldsymbol{\Delta})$. Vertical bars show SE (n=9). cyclopropene 구조의 3번 탄소를 carboxyl ethyl 기로 치환하 더라도 cyclopropene의 탄소간 결합 각도는 큰 영향을 받지 않으므로 DCPE는 cyclopropene과 마찬가지로 높은 strain 에너지를 가질 것으로 예상할 수 있다. 또한 에틸렌 수용체 는 세포막에 분포하는 단백질(3)로서 어떤 화합물이 수용체 에 결합하려면 세포막 접근성을 가져야 한다. 소수성이 강 할 수록 막 지질에 대한 용해도가 증가하여 막 접근성이 향상되는데, 본 연구에서 합성한 $\mathrm{DCPE}$ 는 긴 탄화수소 사슬 의 decyl 치환기를 가지므로 강한 소수성의 특징을 갖는다.

Sisler 등(21)에 따르면, 3번 탄소에 치환기를 가진 1-alkyl cyclopropene은 에틸렌 반응 억제를 위하여 1-MCP 보다 높은 처리 농도가 요구된다. 본 연구에서, $\mathrm{DCPE}$ 는 $4 \times 10^{-4}$ $\mathrm{M}$ 의 액상으로 분무 처리시 $1-\mathrm{MCP}$ 를 $1 \mathrm{ppm}$ 의 농도로 가스 처리한 것과 대등한 수준의 에틸렌 반응 억제효과를 보였 다. 그러나 비록 $\mathrm{DCPE}$ 가 $1-\mathrm{MCP}$ 보다 높은 처리 농도를 요구한다 할지라도, 본 연구에 적용한 정도의 농도 수준에 서 에틸렌 반응 억제효과를 발휘한다면, $1-\mathrm{MCP}$ 에 비하여 물리적 성상이나 안정성 면에서 가지는 장점에 비추어 볼 때, $\mathrm{DCPE}$ 는 안전성만 확보된다면 단감 과실의 수확 후 연화를 지연시키는 약제로의 활용이 가능할 것으로 생각된 다.

\section{요 약}

상온에서 기체로 존재하는 기존의 에틸렌 작용억제제인 $1-\mathrm{MCP}$ 와 달리 상온에서 액상으로 존재하여 분무살포가 가능한 에틸렌 작용억제제를 개발할 목적으로 cyclopropene 유도체의 하나로서 2-decylcyclopropene-1-carboxylic acid ethyl ester(DCPE)를 합성하여 부유 단감을 대상으로 그 처 리효과를 분석하였다. $4 \cdot 10^{-4} \mathrm{M}$ 의 $\mathrm{DCPE}$ 를 수확 전에 분무 살포 처리한 단감을 수확하여 45 일간 저온저장한 후 상온 
$\left(20^{\circ} \mathrm{C}\right)$ 에 1 주간 방치하면서 성숙 관련 지표의 변화를 조사 한 결과, 에틸렌의 작용에 의해 유발되는 과육 연화의 진행 이 효과적으로 지연되었으며, 그 억제 효과는 $1 \mathrm{ppm}$ 의 1-MCP 처리와 대등한 수준이었다. 또한 DCPE는 적어도 한달간 성분 손실 없이 냉장 보관이 가능하였다. 따라서 $\mathrm{DCPE}$ 는 단감 과실의 수확 후 과육의 연화를 지연시키는 약제로의 활용이 가능할 것으로 기대된다.

\section{감사의 글}

본 연구는 농촌진흥청의 연구비 지원에 의해 수행되었음.

\section{Refrences}

1. Abeles FB, Morgan PW, Saltveit ME (1992) Ethylene in plant biology. Academic Press, New York, USA

2. Binder BM (2008) The ethylene receptors : complex perception for a simple gas. Plant Sci, 175, 8-17

3. Solano R, Ecker JR (1998) Ethylene gas : perception, signalling and response. Cur Opinion Plant Biol, 1, 393-398

4. Guo H, Ecker JR (2004) The ethylene signaling pathway : new insights. Cur Opinion Plant Biol, 7, 40-49

5. Hua J, Meyerowitz EM (1998) Ethylene responses are negatively regulated by a receptor gene family in Arabidopsis thaliana. Cell, 94, 261-271

6. Sisler EC, Pian A (1973) Effect of ethylene and cyclic olefins on tobacco leaves. Tobacco Sci, 1, 68-72

7. Sisler EC, Yang SF (1984) Anti-ethylene effects of cis-2-butene and cyclic olefins. Phytochem, 23, 2765-2768

8. Sisler EC (2006) The discovery and development of compounds counteracting ethylene at the receptor level. Biotechnol Advances, 24, 357-367

9. Choi SJ (2010) The change of ethylene production, respiration, and flesh firmness as influenced by treatment with aminoethoxyvinylglycine and 1-methycyclopropene in 'Fuyu' persimmon fruits stored at low temperature. Korean J Hort Sci Technol, 28, 254-258

10. Lelièvre JM, Latchè A, Jones $\mathrm{B}$, Bouzayen $\mathrm{M}$, Pech JC
(1997) Ethylene and fruit ripening. Physiol Plant, 101, 727-739

11. Besada C, Jackman RC, Olsson S, Woolf AB (2010) Response of 'Fuyu' persimmons to ethylene exposure before and during storage. Postharvest Biol Technol, 57, 124-131

12. Itamura $\mathrm{H}$, Kitamura $\mathrm{T}$, Taira $\mathrm{S}$, Harada $\mathrm{H}$, Ito $\mathrm{N}$, Takahashi Y, Fukushima T (1991) Relationship between fruit softening, ethylene production and respiration in Japanese persimmon 'Hiratanenashi'. J Japan Soc Hort Sci, 60, 695-701

13. Takata M (1981) Effects of silver ion on the ripening of Japanese persimmon fruits. J Japan Soc Hort Sci, 50, 372-378

14. Beyer EM (1976) A potent inhibitor of ethylene action in plants. Plant Physiol, 58, 268-271

15. Harima S, Nakano R, Yamauchi S, Kitano Y, Yamamoto Y, Inaba A, Kubo Y (2003) Extending shelf-life of astringent persimmon (Diospyros kaki Thunb.) fruit by 1-MCP. Postharvest Biol Technol, 29, 318-323

16. Luo Z (2007) Effect of 1-methylcyclopropene on ripening of postharvest persimmon (Diospyros kaki L.) fruit. LWT-Food Sci Thechnol, 40, 285-291

17. Blankenship SM, Dole JM (2003) 1-Methylcyclopropene : a review. Postharvest Biol Technol, 28, 1-25

18. Liao L, Zhang F, Yan N, Golen JA, Fox JM (2004) An efficient and general method for resolving cyclopropene carboxylic acids. Tetrahedron, 60, 1803-1816

19. Still WC, Kahn M, Mitra A (1978) Rapid chromatographic technique for preparative separations with moderate resolution. J Org Chem, 43, 2923-2925

20. Schipperijn AJ, Smael P (1973) Chemistry of cyclopropene. II. Formation and reactions of 1-potassio, 1-sodio and 1-lithiocyclopropene in liquid ammonia. Recueil, 92, 1121-1166

21. Sisler EC, Grichko VP, Serek M (2006) Interaction of ethylene and other compounds with the ethylene receptor : agonists and antagonists. Ethylene Action in Plants, Springer-Verlag, Berlin, p 1-34

22. Fisher F, Applequist DE (1965) Synthesis of 1-methylcyclopropene. J Org Chem, 30, 2089-2090 